\title{
Religious Affiliation and Marital Satisfaction: Commonalities Among Christians, Muslims, and Atheists
}

\author{
Piotr Sorokowski, Marta Kowal* and Agnieszka Sorokowska \\ Institute of Psychology, University of Wrocław, Wrocław, Poland
}

Scientists have long been interested in the relationship between religion and numerous aspects of people's lives, such as marriage. This is because religion may differently influence one's level of happiness. Some studies have suggested that Christians have greater marital satisfaction, while others have found evidence that Muslims are more satisfied. Additionally, less-religious people have shown the least marital satisfaction. In the present study, we examined marital satisfaction among both sexes, and among Muslims, Christians, and atheists, using a large, cross-cultural sample from the dataset in Sorokowski et al. (2017). Our results show that men have higher marital satisfaction ratings than women, and that levels of satisfaction do not differ notably among Muslims,

OPEN ACCESS

Edited by:

Masoumeh Velayati, Al-Maktoum College of Higher Education, United Kingdom

Reviewed by:

Nicole Farris,

Texas A\&M University-Commerce,

United States

Ernestine A. W. Duncan,

Norfolk State University, United States

${ }^{*}$ Correspondence: Marta Kowal marta.kowal2@uwr.edu.pl

Specialty section:

This article was submitted to Gender, Sex and Sexualities, a section of the journal

Frontiers in Psychology

Received: 22 June 2019 Accepted: 27 November 2019 Published: 13 December 2019

Citation:

Sorokowski P. Kowal M and Sorokowska A (2019) Religious Affiliation and Marital Satisfaction: Commonalities Among Christians,

Muslims, and Atheists.

Front. Psychol. 10:2798.

doi: 10.3389/fpsyg.2019.02798
Christians, and atheists. We discuss our findings in the context of previous research on the association between marriage and religion.

Keywords: religious affiliation, marital satisfaction, Christians, Muslims, atheists

\section{INTRODUCTION}

Religion has been present nearly since the dawn of human history (Dickson, 1992; Clottes, 2006). Nowadays, it continues to play a key role in most societies (Tarakeshwar et al., 2003). Almost $82 \%$ of the world's people affiliate themselves with a religion. By country, only $5 \%$ of Americans, $4 \%$ of South Africans, $1 \%$ of Brazilians, and 3\% of Indians claim to be atheists (Win-Gallup International Poll, 2012). It therefore seems viable that we should deepen our understanding on how religion influences our lives (Miller and Thoresen, 2003; McCleary and Barro, 2006). As religion is strongly connected with a wide range of relationship-related values and norms (Zarean and Barzegar, 2016), the link between religion and family life has been among the most widely discussed topics in the social sciences (Thomas and Cornwall, 1990; Ammerman and Roof, 1995; Christiano, 2000). The present study aimed to investigate one of those aspects: the association between religion and marital satisfaction.

A large number of studies have addressed marriage in the context of religion (including topics such as marital stability: Heaton and Albrecht, 1991; Lehrer and Chiswick, 1993; Call and Heaton, 1997; Orathinkal and Vansteenwegen, 2006; Brown et al., 2008; Mahoney et al., 2008; Vaaler et al., 2009; marital problem solving: Hünler and Gençöz, 2005; marital fidelity: Dollahite and Lambert, 2007; and marital dependency: Wilson and Musick, 1996). Nevertheless, few data exist on how religious affiliation affects marital satisfaction; and even when studies have taken up this topic, they have had limitations. For example, they have mainly focused on various dimensions of religiosity (e.g., church attendance, religious homogamy, and theological conservatism), and not the specific religion (Schumm et al., 1989; Shehan et al., 1990; Booth et al., 1995; Brandt, 2004; Gaunt, 2006; Vaaler et al., 2009; Wade and Wiloso, 2016); examined people of different religions, but without further comparing the effects of each religion on marital satisfaction (Sullivan, 2001; 
Williams and Lawler, 2003; Olson et al., 2016); looked at members of one religion (Christian: Shehan et al., 1990; Anthony, 1993; Booth et al., 1995; Sullivan, 2001; Williams and Lawler, 2003; Asamarai et al., 2008; Lichter and Carmalt, 2009; Christian and Jewish: Heaton, 1984(Muslim: Al-Othman, 2012; Fard et al., 2013; Al-Darmaki et al., 2016; Mormon: Schramm et al., 2012); been conducted in one country (United States: Brandt, 2004; Marks, 2005; Brown et al., 2008; Schramm et al., 2012; Israel: Gaunt, 2006; Iran: Fard et al., 2013 (United Arab Emirates: Al-Othman, 2012; Al-Darmaki et al., 2016; Ghana: Dabone, 2012); or included only low-income married couples (Lichter and Carmalt, 2009).

Furthermore, results from those studies brought mixed results. Some research has suggested that religious couples are happier with their marriages than are non-religious couples (Ortega et al., 1988; Anthony, 1993; Brandt, 2004; Mahoney et al., 2008; Schramm et al., 2012), with Christians showing greater happiness than Muslims (Lev-Wiesel and Al-Krenawi, 1999, but for contradictory results see Abu-Rayya, 2007), while other studies have provided evidence of a weak association between marital satisfaction and religion (Booth et al., 1995; Sullivan, 2001; Gaunt, 2006; Orathinkal and Vansteenwegen, 2006; AlOthman, 2012; Fard et al., 2013), and a few indicated there is no link (Williams and Lawler, 2003; Luo and Klohnen, 2005; Dabone, 2012; Olson et al., 2016).

There is even less evidence of the relationship between atheism and marital satisfaction. Some studies have shown a positive association between religiosity and marital satisfaction (Lichter and Carmalt, 2009; Wilcox and Wolfinger, 2008), or mental well-being (Galen and Kloet, 2011), which would suggest atheists (at the low end of the religiosity continuum) may have lower indicators of marital happiness than religious adherents. Nevertheless, to date, researchers have not directly addressed the issue of atheists in the marriage context, as existing studies have generally focused on religious married couples (Giblin, 1997; Fincham et al., 2011), thus excluding the relatively large number of atheists. These prevent drawing of certain conclusions about marital satisfaction among non-religious people.

In sum, no cross-cultural studies have compared marital satisfaction among people of various religious affiliations (or nonreligious: atheists). One can only hypothesize why scientists are not willing to tackle this issue. One reason might be that such comparisons are often perceived as politically incorrect (Raines, 1996). Nevertheless, comparisons within a single religion or culture do not permit generalization of the conclusions, as people of different religious affiliations might be subject to different, culture-specific pressures and situations (Tarakeshwar et al., 2003). To fill this gap in knowledge, the present study aimed to analyze the relationship between religious affiliation and marital satisfaction, in a large, cross-cultural sample.

\section{MATERIALS AND METHODS}

\section{Participants}

We used data from the dataset published in Sorokowski et al. (2017), a study conducted between July 2012 and December
2013. Participants, after providing informed consent, completed a written questionnaire (except in two countries where data were collected online), and were not compensated for their participation (except in one country where participants received 50 Hong Kong dollars). See Sorokowski et al. (2017) for more details regarding the participants in the dataset.

The present study's main goal was to compare people from the world's most common religions (Grim et al., 2015). The Sorokowski et al. (2017) dataset included Protestants, Christians, Jews, Muslims, Buddhists, Atheists, Jehovah's Witnesses, Evangelicals, Spiritualists, Orthodox, Hindus, and others not of the aforementioned religious affiliations. Despite this wide representation, we decided to only analyze answers provided by Christians, Muslims, and atheists, as these were the most highly represented religious and non-religious samples deriving from the different countries in the dataset (Christians from 27 countries; Muslims from 23 countries, and atheists from 27 countries; see Tables 1, 2). Thus, in contrast with studies of people from a single country (e.g., Brown et al., 2008; Vaaler et al., 2009), our study aimed to compare religious affiliation and marital satisfaction among various nationalities.

In total, analysis included answers of 5,195 participants [mean age: 41.35 ; standard deviation (SD): 11.54; range: $18-88$ years], among whom 2,393 (46.06\%) were men.

\section{Procedure}

All questionnaires were translated into the participants' local language (with the exception of English-speaking countries, where questionnaires were administered in their original wording), using back-translation (Brislin, 1970). Participants were surveyed (inter alia) via two questionnaires that inquired on marital satisfaction. In the present study, one questionnaire, the Kansas Marital Satisfaction Scale (KMSS) (Nichols et al., 1983; Schumm et al., 1986), was included in the analysis. The KMSS is a well-established and commonly used tool for assessing satisfactory psychometric characteristics (Schumm et al., 1986; Crane et al., 2000), and was successfully used in studies involving non-Western samples (Shek and Tsang, 1993). Sorokowski et al. (2017) found the scale was culturally equivalent (Tucker's phi coefficient from 0.92 to 1 ), and reliable (Cronbach's alpha on the pooled data reached 0.94). Questions from the scale include: "How satisfied are you with your marriage?" and "How satisfied are you with your wife/husband as a spouse?" Participants answered each item on a seven-point scale ranging from 1 (extremely dissatisfied) to 7 (extremely satisfied). In all subsequent analysis, as a measure of marital satisfaction we used mean scores of each participant's KMSS answers.

Participants were asked directly about their religious affiliation. Certain variables that in previous studies have been shown to correlate with marital satisfaction-such as age, length of relationship, education, number of children, and material situation (Bradbury et al., 2000; Twenge et al., 2003; Sorokowski et al., 2017)-were also included in the analysis. Detailed information about the procedure for data collection can be found in Sorokowski et al. (2017). 
TABLE 1 | Characteristics of study population's religious affiliation and sex distribution from each country.

\begin{tabular}{|c|c|c|c|c|c|c|c|c|c|c|}
\hline \multirow[t]{3}{*}{ Country } & \multirow{3}{*}{$\begin{array}{c}\text { Total number of } \\
\text { participants }\end{array}$} & \multicolumn{9}{|c|}{ Religion } \\
\hline & & \multicolumn{3}{|c|}{ Christians } & \multicolumn{3}{|c|}{ Muslims } & \multicolumn{3}{|c|}{ Atheists } \\
\hline & & Men & Women & Total & Men & Women & Total & Men & Women & Total \\
\hline Brazil & 256 & 90 & 46 & 136 & 8 & 13 & 21 & 61 & 38 & 99 \\
\hline Bulgaria & 1 & 0 & 0 & 0 & 1 & 0 & 1 & 0 & 0 & 0 \\
\hline Canada & 55 & 6 & 7 & 13 & 2 & 1 & 3 & 12 & 27 & 39 \\
\hline China & 106 & 0 & 1 & 1 & 0 & 2 & 2 & 43 & 60 & 103 \\
\hline Croatia & 585 & 224 & 250 & 474 & 4 & 1 & 5 & 62 & 44 & 106 \\
\hline Estonia & 97 & 0 & 4 & 4 & 0 & 0 & 0 & 36 & 57 & 93 \\
\hline Germany & 69 & 6 & 8 & 14 & 0 & 1 & 1 & 20 & 34 & 54 \\
\hline Ghana & 35 & 13 & 12 & 25 & 3 & 3 & 6 & 1 & 3 & 4 \\
\hline Greece & 9 & 0 & 0 & 0 & 0 & 0 & 0 & 5 & 4 & 9 \\
\hline Hong Kong & 65 & 11 & 4 & 15 & 0 & 0 & 0 & 31 & 19 & 50 \\
\hline Hungary & 225 & 48 & 116 & 164 & 0 & 0 & 0 & 22 & 39 & 61 \\
\hline India & 33 & 3 & 1 & 4 & 7 & 12 & 19 & 5 & 5 & 10 \\
\hline Indonesia & 4 & 0 & 0 & 0 & 0 & 3 & 3 & 1 & 0 & 1 \\
\hline Iran & 587 & 0 & 0 & 0 & 258 & 329 & 587 & 0 & 0 & 0 \\
\hline Italy & 306 & 94 & 181 & 275 & 0 & 0 & 0 & 24 & 7 & 31 \\
\hline Kazakhstan & 70 & 10 & 10 & 20 & 28 & 22 & 50 & 0 & 0 & 0 \\
\hline Kenia & 43 & 16 & 16 & 32 & 4 & 6 & 10 & 1 & 0 & 1 \\
\hline Malaysia & 87 & 1 & 0 & 1 & 40 & 46 & 86 & 0 & 0 & 0 \\
\hline Mexico & 138 & 59 & 63 & 122 & 1 & 1 & 2 & 6 & 8 & 14 \\
\hline Nigeria & 301 & 119 & 100 & 219 & 14 & 38 & 52 & 13 & 17 & 30 \\
\hline Pakistan & 130 & 0 & 0 & 0 & 59 & 71 & 130 & 0 & 0 & 0 \\
\hline Poland & 434 & 152 & 256 & 408 & 0 & 0 & 0 & 13 & 13 & 26 \\
\hline Portugal & 271 & 84 & 160 & 244 & 0 & 2 & 2 & 15 & 10 & 25 \\
\hline Romania & 6 & 1 & 3 & 4 & 0 & 0 & 0 & 0 & 2 & 2 \\
\hline Russia & 31 & 0 & 2 & 2 & 0 & 0 & 0 & 22 & 7 & 29 \\
\hline Saudi Arabia & 198 & 0 & 0 & 0 & 86 & 112 & 198 & 0 & 0 & 0 \\
\hline Slovakia & 216 & 39 & 112 & 151 & 0 & 0 & 0 & 30 & 35 & 65 \\
\hline South Korea & 33 & 3 & 1 & 4 & 0 & 0 & 0 & 18 & 11 & 29 \\
\hline Spain & 197 & 61 & 73 & 134 & 1 & 0 & 1 & 29 & 33 & 62 \\
\hline Switzerland & 107 & 42 & 18 & 60 & 0 & 2 & 2 & 26 & 19 & 45 \\
\hline Turkey & 390 & 1 & 0 & 1 & 228 & 146 & 374 & 10 & 5 & 15 \\
\hline United Kingdom & 61 & 8 & 14 & 22 & 2 & 1 & 3 & 20 & 16 & 36 \\
\hline Uganda & 50 & 22 & 11 & 33 & 6 & 9 & 15 & 1 & 1 & 2 \\
\hline
\end{tabular}

TABLE 2 | Characteristics of studied Christians, Muslims, and atheists, and their marital satisfaction.

\begin{tabular}{lccc}
\hline Religion & $\begin{array}{c}\text { Number of } \\
\text { countries }\end{array}$ & $\begin{array}{c}\text { Number of } \\
\text { participants }\end{array}$ & $\begin{array}{c}\text { Marital } \\
\text { satisfaction }\end{array}$ \\
\hline Christian & 27 & 2582 & $5.69(\mathrm{SD}=1.42)$ \\
Muslim & 23 & 1572 & $5.72(\mathrm{SD}=1.42)$ \\
Atheistic & 27 & 1041 & $5.69(\mathrm{SD}=1.43)$ \\
\hline
\end{tabular}

\section{RESULTS}

We conducted an analysis of covariance to determine the relation between religious affiliation and marital satisfaction. There was a non-significant effect of the former on the latter, after controlling for sex, age, length of marriage, number of children, education, and material situation $[F(2,5194)=1.11$, $p=0.33]$. Analysis showed that some variables were significant covariates, including: age $[F(1,5194)=6.99, p<0.05]$; material status $[F(1,5194)=98.34, p<0.001]$; and $\operatorname{sex}[F(1,5194)=34.28$, $p<0.001]$. Overall, men $($ mean $=5.83, \mathrm{SD}=1.34)$ had higher marital satisfaction than women (mean $=5.59$, $\mathrm{SD}=1.48)($ see Figure 1). Nevertheless, this effect was extremely weak $($ Eta $<0.01)$.

\section{DISCUSSION}

The present study's primary goal was to examine the association between religious affiliation and marital satisfaction, and the results showed that there was no relationship between the former and level of the latter-Christians and Muslims were found to be similarly satisfied with their marriages, as were atheists. 


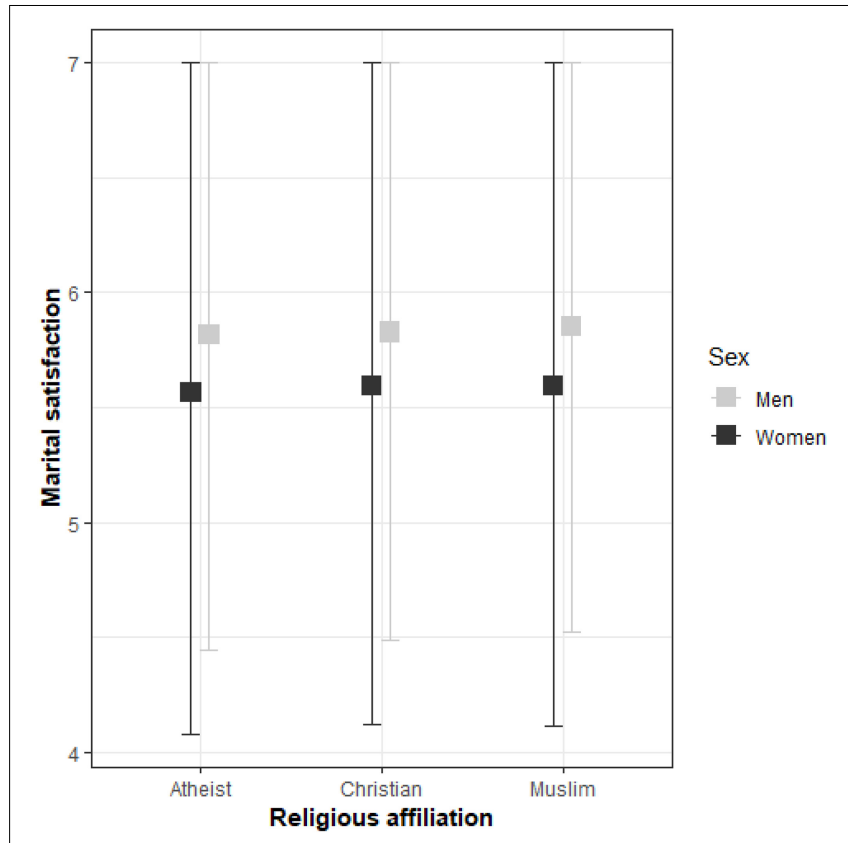

FIGURE 1 | Men's and women's marital satisfaction among the studied Christians, Muslims, and atheists.

Nevertheless, the present analysis provided support for a link between marital satisfaction and age (younger people showed higher marital happiness), material status (higher material status, higher marital satisfaction), or sex (men were happier in their marriages than women).

Previous findings have indicated Abrahamic religions (e.g., Christianity, Islam) share many similarities (Agius and Chircop, 1998; Zarean and Barzegar, 2016) and promote formation of traditional family ties, such as marriage rather than cohabitation, and marital rather than non-marital births (Dollahite and Lambert, 2007; Zarean and Barzegar, 2016). However, these religions have some substantive differences in beliefs and practices. For example, polygyny is not accepted in Christianity, whereas it is widely accepted in Islam, and such a family model may negatively influence marital life (Al-Krenawi and Graham, 2006). Despite the discrepancies between those two religions, the present study found no differences between them as far as marital satisfaction, and this included people from different parts of the world.

Moreover, since the New York City terrorist attacks on September 11, 2001, Islam has been central in many debates, discussions, and publications (Alghafli et al., 2014). Discussion on Islam frequently concerns familial issues, perceived by the Western media mostly in a negative light. Problematic issues include, for instance, gender roles and the treatment of women (McDonald, 2006; Ridouani, 2011; Ennaji, 2016). Studies, however, do not support this unfavorable view of females' situations: religious Muslims show increased marital satisfaction (Abdel-Khalek, 2006, 2010; Asamarai et al., 2008; Ahmadi and Hossein-Abadi, 2009; Zaheri et al., 2016, but see also Abu-Rayya, 2007).
The present study's results provide evidence that Christians and Muslims do not differ in their level of marital satisfaction. People from various countries identifying themselves as belonging to one of these two religions had similar level of marital happiness, which is consistent with previous findings. For instance, Dabone (2012) compared marital satisfaction among Muslim and Christian spouses, and found relative dissatisfaction, while the religious affiliation did not affect the satisfaction.

As scarce data exist on marital satisfaction among atheists, the present study's second aim was to investigate whether atheists have similar marital satisfaction to marriages as do religious adherents. Considering positive correlations found between religiosity and marital satisfaction (Marks, 2005), atheists may be expected to have significantly lower levels of both variables. A major drawback of previous related research is its predominant focus on comparisons between more-religious and less-religious people (Fincham et al., 2011), excluding the relatively large group that atheists represent. Additionally, most studies have been conducted in the United States, where atheists are often negatively stereotyped (Zuckerman, 2009). The present study results provide evidence that atheists are neither more nor less satisfied with their marriages than religious adherents, which suggests religion may not influence marital satisfaction.

There are a few possible explanations for observed similar marital satisfaction ratings across people of different religions. Overall, married couples constitute a lower percentage of people in a relationship (Nock, 1995). Those who decide to get married may be particularly committed or well-suited to partnership, regardless of their religious affiliation. Entering a serious relationship, such as marriage, requires strong enthusiasm toward the partner (Wang and Chang, 2002) and, thus, results in higher ratings of subjectively perceived relationship satisfaction. Another possible explanation may be that people generally consider marriage a long-lasting relationship (Silliman and Schumm, 2004; Willoughby and Dworkin, 2009), and when they decide to get married, they rationalize and "cognitively close" their choice (Webster and Kruglanski, 1994). Participants in the study population may have felt they had to be satisfied with their relationship, as they had invested so much energy into its development. Had they reported being unsatisfied, feeling an internal conflict may have surfaced (e.g., "Why am I even with him/her if it makes me unhappy?"). The need to explain the dissonance of staying in an unsuccessful relationship would be negatively perceived, and could yield unpleasant emotions, especially in Western, individualistic cultures, which value the pursuit of personal happiness at all costs (Gilovich et al., 2015). Such emotion could also occur in Eastern, collectivistic cultures, which emphasize the importance of being unselfish, grateful, and appreciative of one's partner (Kagawa-Fox, 2010).

In general, participants were relatively satisfied with their marriages. Nonetheless, men's marital satisfaction differed from women's (independent of religious affiliation). Over 40 years ago, Bernard (1975) presented a provocative and controversial thesis asserting marriage is better for men than for women, and his statement has raised heated discussions. Most of the research 
has provided evidence for to support Bernard's (1975) that thesis (Fowers, 1991; Schumm et al., 1998), and this is also true in nonWestern cultures (Shek and Tsang, 1993; Asamarai et al., 2008). However, there was also one study which yielded unclear findings (McNulty et al., 2008). Results of the present study - which is based on the analysis of a large, cross-cultural sample, confirm the differences among men's and women's marital satisfaction: husbands did indeed have higher marital satisfaction than wives. Nevertheless, the size effect of these sex differences was extremely small $($ Eta $<0.01)$.

In conclusion, despite a large body of research on marital satisfaction (Bradbury et al., 2000; Twenge et al., 2003; Hilpert et al., 2016), most studies have rarely controlled for participants' religion. Even when they have done so, they have not explored the differences between people of various religious affiliations (Sullivan, 2001; Williams and Lawler, 2003; Olson et al., 2016). Future research should therefore focus on people of different (1) religions (especially lessprevalent ones); and (2) cultures (as most studies up to date have been conducted on Western, educated, industrialized, rich, and democratic populations (Henrich et al., 2010), and should take into consideration other factors that may influence marital satisfaction among people of different religious affiliations (e.g., number of children, education, country's development), as this would provide further understanding on the interaction between religion and marital happiness, as well as culture.

\section{REFERENCES}

Abdel-Khalek, A. M. (2006). Happiness, health, and religiosity: significant relations. Ment. Health Relig. Cult. 9, 85-97. doi: 10.1080/1369467050004 0625

Abdel-Khalek, A. M. (2010). Quality of life, subjective well-being, and religiosity in Muslim college students. Qual. Life Res. 19, 1133-1143. doi: 10.1007/s11136010-9676-7

Abu-Rayya, H. M. (2007). Acculturation, Christian religiosity, and psychological and marital well-being among the European wives of Arabs in Israel. Ment. Health Relig. Cult. 10, 171-190. doi: 10.1080/13694670500504901

Agius, E., and Chircop, L. (1998). Caring for Future Generations: Jewish, Christian, and Islamic Perspectives. Westport, CT: Praeger.

Ahmadi, K., and Hossein-Abadi, F. H. (2009). Religiosity, marital satisfaction and child rearing. Pastoral Psychol. 57, 211-221. doi: 10.1007/s11089-008-0176-4

Al-Darmaki, F. R., Hassane, S. H., Ahammed, S., Abdullah, A. S., Yaaqeib, S. I., and Dodeen, H. (2016). Marital satisfaction in the United Arab Emirates: development and validation of a culturally relevant scale. J. Fam. Issues 37, 1703-1729. doi: 10.1177/0192513X14547418

Alghafli, Z., Hatch, T., and Marks, L. (2014). Religion and relationships in Muslim families: a qualitative examination of devout married Muslim couples. Religions 5, 814-833. doi: 10.3390/rel5030814

Al-Krenawi, A., and Graham, J. R. (2006). A comparison of family functioning, life and marital satisfaction, and mental health of women in polygamous and monogamous marriages. Int. J. Soc. Psychiatry 52, 5-17. doi: 10.1177/ 00207640060061245

Al-Othman, H. M. (2012). Marital happiness of married couples in the U.A.E society: a sample from Sharjah. Asian Soc. Sci. 8, 217-224. doi: 10.5539/ass. v8n 4 p 217

Ammerman, N. T., and Roof, W. C. (1995). "Introduction: old patterns, new trends, fragile experiments," in Work, Family, and Religion in Contemporary Society, eds N. Ammerman, and W. C. Roof, (New York, NY: Routledge), 1-20.

\section{DATA AVAILABILITY STATEMENT}

Publicly available datasets were analyzed in this study. This data can be found here: https://figshare.com/s/ d2bd33a9605a3a204881.

\section{ETHICS STATEMENT}

The studies involving human participants were reviewed and approved by the Institutional Review Board of the Institute of Psychology, University of Wrocław. The patients/participants provided their written informed consent to participate in this study.

\section{AUTHOR CONTRIBUTIONS}

All authors contributed in conducting the statistical analysis and preparing the manuscript.

\section{ACKNOWLEDGMENTS}

We thank Adam Goulston, MS, ELS, from Edanz Group (www. edanzediting.com/ac) for editing the draft of this manuscript.

Anthony, M. J. (1993). The relationship between marital satisfaction and religious maturity. Relig. Educ. 88, 97-108. doi: 10.1080/0034408930880108

Asamarai, L. A., Solberg, K. B., and Solon, P. C. (2008). The role of religiosity in Muslim spouse selection and its influence on marital satisfaction. J. Muslim Ment. Health 3, 37-52. doi: 10.1080/15564900802006459

Bernard, J. (1975). The Future of Marriage. New York, NY: Bantam books.

Booth, A., Johnson, D. R., Branaman, A., and Sica, A. (1995). Belief and behavior: does religion matter in today's marriage? J. Marriage Fam. 57, 661-667. doi: $10.2307 / 353921$

Bradbury, T. N., Fincham, F. D., and Beach, S. R. H. (2000). Research on the nature and determinants of marital satisfaction: a decade in review. J. Marriage Fam. 62, 964-980. doi: 10.1111/j.1741-3737.2000.00964.x

Brandt, S. (2004). Religious homogamy and marital satisfaction: couples that pray together, stay together. Sociol. Viewp. 20, 11-20.

Brislin, R. W. (1970). Back-translation for cross-cultural research. J. Cross Cult. Psychol. 1, 185-216. doi: 10.1177/135910457000100301

Brown, E., Orbuch, T. L., \& Bauermeister, J. A. (2008). Religiosity and marital stability among black American and white American couples. Fam. Relat. 57, 186-197. doi: 10.1111/j.1741-3729.2008.00493.x

Call, V. R. A., and Heaton, T. B. (1997). Religious influence on marital stability. J. Sci. Stud. Relig. 36, 382-392. doi: 10.2307/1387856

Christiano, K. (2000). "Religion and the family in modern American culture," in Family, Religion, and Social Change in Diverse Societies, eds S. Houseknecht, and P. Pankhurst, (Oxford: Oxford University Press), 43-78.

Clottes, J. (2006). "Spirituality and religion in paleolithic times," in The Evolution of Rationality: Interdisciplinary Essays in Honor of J. Wentzel van Huyssteen, ed. F. LeRon Shults, (Cambridge: Eerdmans), 133-148.

Crane, D. R., Middleton, K. C., and Bean, R. A. (2000). Establishing criterion scores for the Kansas marital satisfaction scale and the revised dyadic adjustment scale. Am. J. Fam. Ther. 28, 53-60. doi: 10.1080/019261800261815

Dabone, K. T. (2012). Marital Satisfaction Among Married People in Sunyani Municipality. Doctoral dissertation, University of Cape Coast, Ghana. 
Dickson, D. B. (1992). The Dawn of Belief: Religion in the Upper Paleolithic of Southwestern Europe. Tucson: University of Arizona Press.

Dollahite, D. C., and Lambert, N. M. (2007). Forsaking all others: how religious involvement promotes marital fidelity in Christian, Jewish, and Muslim couples. Rev. Relig. Res. 48, 290-307.

Ennaji, M. (ed) (2016). New Horizons of. (Muslim)Diaspora in North America and Europe. New York, NY: Palgrave Macmillan.

Fard, M. K., Shahabi, R., and Zardkhaneh, S. A. (2013). Religiosity and marital satisfaction. Procedia Soc. Behav. Sci. 82, 307-311. doi: 10.1016/j.sbspro.2013. 06.266

Fincham, F. D., Ajayi, C., and Beach, S. R. H. (2011). Spirituality and marital satisfaction in African American couples. Psychol. Relig. Spiritual. 3, 259-268. doi: $10.1037 / \mathrm{a} 0023909$

Fowers, B. J. (1991). His and her marriage: a multivariate study of gender and marital satisfaction. Sex Roles 24, 209-221. doi: 10.1007/BF00288892

Galen, L. W., and Kloet, J. D. (2011). Mental well-being in the religious and the non-religious: evidence for a curvilinear relationship. Ment. Health Relig. Cult. 14, 673-689. doi: 10.1080/13674676.2010.510829

Gaunt, R. (2006). Couple similarity and marital satisfaction: are similar spouses happier? J. Personal. 74, 1401-1420. doi: 10.1111/j.1467-6494.2006.00414.x

Giblin, P. R. (1997). Marital spirituality: a quantitative study. J. Relig. Health 36, 333-344.

Gilovich, T., Kumar, A., and Jampol, L. (2015). A wonderful life: experiential consumption and the pursuit of happiness. J. Consum. Psychol. 25, 152-165. doi: $10.1016 /$ j.jcps.2014.08.004

Grim, B., Johnson, T., Skirbekk, V., and Zurlo, G. (2015). Yearbook of International Religious Demography 2015. Netherlands: Brill.

Heaton, T. B. (1984). Religious homogamy and marital satisfaction reconsidered. J. Marriage Fam. 46, 729-733. doi: 10.2307/352615

Heaton, T. B., and Albrecht, S. L. (1991). Stable unhappy marriages. J. Marriage Fam. 53, 747-758. doi: 10.2307/352748

Henrich, J., Heine, S. J., and Norenzayan, A. (2010). Most people are not WEIRD. Nature 466:29. doi: 10.1038/466029a

Hilpert, P., Randall, A. K., Sorokowski, P., Atkins, D. C., Sorokowska, A., Ahmadi, K., et al. (2016). The associations of dyadic coping and relationship satisfaction vary between and within nations: a 35-nation study. Front. Psychol. 7:1106. doi: 10.3389/fpsyg.2016.01106

Hünler, O. S., and Gençöz, T. (2005). The effect of religiousness on marital satisfaction: testing the mediator role of marital problem solving between religiousness and marital satisfaction relationship. Contemp. Fam. Ther. 27, 123-136. doi: 10.1007/s10591-004-1974-1

Kagawa-Fox, M. (2010). Environmental ethics from the Japanese perspective. Ethics Place Environ. 13, 57-73. doi: 10.1080/13668790903554204

Lehrer, E. L., and Chiswick, C. U. (1993). Religion as a determinant of marital stability. Demography 30, 385-404. doi: 10.2307/2061647

Lev-Wiesel, R., and Al-Krenawi, A. (1999). Attitude towards marriage and marital quality: a comparison among Israeli Arabs differentiated by religion. Fam. Relat. 48, 51-56. doi: 10.2307/585682

Lichter, D. T., and Carmalt, J. H. (2009). Religion and marital quality among low-income couples. Soc. Sci. Res. 38, 168-187. doi: 10.1016/j.ssresearch.2008. 07.003

Luo, S., and Klohnen, E. C. (2005). Assortative mating and marital quality in newlyweds: a couple-centered approach. J. Pers. Soc. Psychol. 88, 304-326. doi: 10.1037/0022-3514.88.2.304

Mahoney, A., Pargament, K. I., Tarakeshwar, N., and Swank, A. B. (2008). Religion in the home in the 1980s and 1990s: a meta-analytic review and conceptual analysis of links between religion, marriage, and parenting. J. Fam. Psychol. 15, 559-596. doi: 10.1037//0893-3200.15.4.559

Marks, L. (2005). How does religion influence marriage? Christian, Jewish, Mormon, and Muslim perspectives. Marriage Fam. Rev. 38, 85-111. doi: 10. 1300/J002v38n01_07

McCleary, R. M., and Barro, R. J. (2006). Religion and economy. J. Econ. Perspect. 20, 49-72. doi: 10.1257/jep.20.2.49

McDonald, L. (2006). "Gender and family-Major dimensions of retirement research," in New Frontiers of Research on Retirement, ed. L. O. Stone, (Ottawa: Minister of Industry), 129-136.

McNulty, J. K., Neff, L. A., and Karney, B. R. (2008). Beyond initial attraction: physical attractiveness in newlywed marriage. J. Fam. Psychol. 22, 135-143. doi: 10.1037/0893-3200.22.1.135
Miller, W. R., and Thoresen, C. E. (2003). Spirituality, religion, and health: an emerging research field. Am. Psychol. 58, 24-35. doi: 10.1037/0003-066X. 58.1.24

Nichols, C. W., Schumm, W. R., Schectman, K. L., and Grigsby, C. C. (1983). Characteristics of responses to the Kansas marital satisfaction scale by a sample of 84 married mothers. Psychol. Rep. 53, 567-572. doi: 10.2466/pr0.1983.53. 2.567

Nock, S. L. (1995). A comparison of marriages and cohabiting relationships. J. Fam. Issues 16, 53-76. doi: 10.1177/019251395016001004

Olson, J. R., Marshall, J. P., Goddard, H. W., and Schramm, D. G. (2016). Variations in predictors of marital satisfaction across more religious and less religious regions of the United States. J. Fam. Issues 37, 1658-1677. doi: 10.1177/ 0192513 X14560643

Orathinkal, J., and Vansteenwegen, A. (2006). Religiosity and marital satisfaction. Contemp. Fam. Ther. 28, 497-504. doi: 10.1007/s10591-0069020-0

Ortega, S. T., Whitt, H. P., and William, J. A. (1988). Religious homogamy and marital happiness. J. Fam. Issues 9, 224-239. doi: 10.1177/019251388009002005

Raines, J. C. (1996). The politics of religious correctness: Islam and the West. Cross Curr. 46, 39-49.

Ridouani, D. (2011). The representation of Arabs and Muslims in Western media. RUTA Comun. 3, 1-14.

Schramm, D. G., Marshall, J. P., Harris, V. W., and Lee, T. R. (2012). Religiosity, homogamy, and marital adjustment: an examination of newlyweds in first marriages and remarriages. J. Fam. Issues 33, 246-268. doi: 10.1177/ $0192513 X 11420370$

Schumm, W. R., Obiorah, F. C., and Silliman, B. (1989). Marital quality as a function of conservative religious identification in a sample of Protestant and Catholic wives from the Midwest. Psychol. Rep. 64, 124-126. doi: 10.2466/pr0. 1989.64.1.124

Schumm, W. R., Paff-Bergen, L. A., Hatch, R. C., Obiorah, F. C., Copeland, J. M., Meens, L. D., et al. (1986). Concurrent and discriminant validity of the kansas marital satisfaction scale. J. Marriage Fam. 48, 381-387.

Schumm, W. R., Webb, F. J., and Bollman, S. R. (1998). Gender and marital satisfaction: data from the national survey of families and households. Psychol. Rep. 83, 319-327. doi: 10.2466/pr0.1998.83.1.319

Shehan, C. L., Bock, E. W., and Lee, G. R. (1990). Religious heterogamy, religiosity, and marital happiness: the case of Catholics. J. Marriage Fam. 52, 73-79. doi: $10.2307 / 352839$

Shek, D. T., and Tsang, S. K. (1993). The Chinese version of the kansas marital satisfaction scale: some psychometric and normative data. Soc. Behav. Pers. Int. J. 21, 205-214. doi: 10.2224/sbp.1993.21.3.205

Silliman, B., and Schumm, W. R. (2004). Adolescents' perceptions of marriage and premarital couples education. Fam. Relat. 53, 513-520. doi: 10.1111/j.01976664.2004.00060.x

Sorokowski, P., Randall, A. K., Groyecka, A., Frackowiak, T., Cantarero, K., Hilpert, P., et al. (2017). Marital satisfaction, sex, age, marriage duration, religion, number of children, economic status, education, and collectivistic values: data from 33 countries. Front. Psychol. 8:1199. doi: 10.3389/fpsyg.2017. 01199

Sullivan, K. T. (2001). Understanding the relationship between religiosity and marriage: an investigation of the immediate and longitudinal effects of religiosity on newlywed couples. J. Fam. Psychol. 15, 610-626. doi: 10.1037/ 0893-3200.15.4.610

Tarakeshwar, N., Stanton, J., and Pargament, K. I. (2003). Religion: an overlooked dimension in cross-cultural psychology. J. Cross Cult. Psychol. 34, 377-394. doi: 10.1177/0022022103034004001

Thomas, D. L., and Cornwall, M. (1990). Religion and family in the 1980s: discovery and development. J. Marriage Fam. 52, 983-992. doi: 10.2307/ 353314

Twenge, J. M., Campbell, W. K., and Foster, C. A. (2003). Parenthood and marital satisfaction: a meta-analytic review. J. Marriage Fam. 65, 574-583. doi: 10.1111/ j.1741-3737.2003.00574.x

Vaaler, M. L., Ellison, C. G., and Powers, D. A. (2009). Religious influences on the risk of marital dissolution. J. Marriage Fam. 71, 917-934. doi: 10.1111/j.17413737.2009.00644.x

Wade, J. C., and Wiloso, P. G. (2016). Religiosity, masculinity, and marital satisfaction among javanese Muslim men. Int. J. Res. Stud. Psychol. 5, 37-52. doi: $10.5861 /$ ijrsp.2016.1468 
Wang, H. Z., and Chang, S. M. (2002). The commodification of international marriages: cross-border marriage business in Taiwan and Viet Nam. Int. Migr. 40, 93-116. doi: 10.1111/1468-2435.00224

Webster, D. M., and Kruglanski, A. W. (1994). Individual differences in need for cognitive closure. J. Pers. Soc. Psychol. 67, 1049-1062. doi: 10.1037/0022-3514. 67.6.1049

Wilcox, W. B., and Wolfinger, N. H. (2008). Living and loving “decent”: religion and relationship quality among urban parents. Soc. Sci. Res. 37, 828-843. doi: 10.1016/j.ssresearch.2007.11.001

Williams, L. M., and Lawler, M. G. (2003). Marital satisfaction and religious heterogamy: a comparison of interchurch and same-church individuals. J. Fam. Issues 24, 1070-1092. doi: 10.1177/0192513X03256497

Willoughby, B. J., and Dworkin, J. (2009). The relationships between emerging adults' expressed desire to marry and frequency of participation in risk-taking behaviors. Youth Soc. 40, 426-450. doi: 10.1177/0044118X08318116

Wilson, J., and Musick, M. (1996). Religion and marital dependency. J. Sci. Stud. Relig. 35, 30-40. doi: 10.2307/1386393

Win-Gallup International Poll (2012). Global Index of Religion and Atheism. Available at: http://redcresearch.ie/wp-content/uploads/2012/08/RED-Cpress-release-Religion-and-Atheism-25-7-12.pdf (accessed January 13, 2015).
Zaheri, F., Dolatian, M., Shariati, M., Simbar, M., Ebadi, A., and Hasanpoor Azghadi, S. B. (2016). Effective factors in marital satisfaction in perspective of Iranian women and men: a systematic review. Electron. Phys. 8, 3369-3377. doi: $10.19082 / 3369$

Zarean, M., and Barzegar, K. (2016). Marriage in Islam, Christianity, and Judaism. Relig. Inquiries 5, 67-80.

Zuckerman, P. (2009). Atheism, secularity, and well-being: how the findings of social science counter negative stereotypes and assumptions. Sociol. Compass 3, 949-971. doi: 10.1111/j.1751-9020.2009.00247.x

Conflict of Interest: The authors declare that the research was conducted in the absence of any commercial or financial relationships that could be construed as a potential conflict of interest.

Copyright (c) 2019 Sorokowski, Kowal and Sorokowska. This is an open-access article distributed under the terms of the Creative Commons Attribution License (CC BY). The use, distribution or reproduction in other forums is permitted, provided the original author(s) and the copyright owner(s) are credited and that the original publication in this journal is cited, in accordance with accepted academic practice. No use, distribution or reproduction is permitted which does not comply with these terms. 